Relations industrielles

Industrial Relations

\title{
Walter P. Reuther - Selected Papers. Edité par Henry M. Christman; The Macmillan Company, New York, 1961, 330 pp.
}

\section{Jean-Réal Cadrin}

Volume 17, numéro 1, janvier 1962

URI : https://id.erudit.org/iderudit/1021664ar

DOI : https://doi.org/10.7202/1021664ar

Aller au sommaire du numéro

Éditeur(s)

Département des relations industrielles de l’Université Laval

ISSN

0034-379X (imprimé)

1703-8138 (numérique)

Découvrir la revue

Citer ce compte rendu

Cadrin, J.-R. (1962). Compte rendu de [Walter P. Reuther - Selected Papers.

Edité par Henry M. Christman; The Macmillan Company, New York, 1961, 330

pp.] Relations industrielles / Industrial Relations, 17(1), 92-92.

https://doi.org/10.7202/1021664ar

Tous droits réservés (C Département des relations industrielles de l’Université Laval, 1962
Ce document est protégé par la loi sur le droit d'auteur. L'utilisation des services d'Érudit (y compris la reproduction) est assujettie à sa politique d'utilisation que vous pouvez consulter en ligne.

https://apropos.erudit.org/fr/usagers/politique-dutilisation/ 


\section{tion de l'Etat.}

La régime des négociations collectives, contrairement à ce que l'on rencontre dans nos pays d'Amérique, est fortement centralisé. La Confédération des employeurs comme la Centrale syndicale possèdent sur leurs affiliés des pouvoirs qui seraient difficilement admis chez nous. Mais ce sont là des pratiques qui se comprennent quand on tient compte du contexte historique, culturel et économique du développement des relations professionnelles dans ce pays.

\section{GÉrard Dion}

Walter P. Reuther - Selected Papers. Edité par Henry M. Christman; The Macmillan Company, New York, 1961, $330 \mathrm{pp}$.

Nous avions eu en 1949 l'ouvrage monographique de Irving Howe et R. J. Widick, The U.A.W. and Walter Reuther \& dans lequel Reuther nous était raconté; dans la collection de textes choisis que nous présente maintenant Christman, c'est Walter Reuther luimême qui parle sur les principaux problèmes qui ont accaparé son attention au cours de sa brillante et fructueuse carrière de chef syndicaliste.

Il fallait que la pensée d'un homme aux responsabilités si lourdes de sens pour le mouvement syndical américain ainsi que pour l'ensemble de l'économie de nos voisins du Sud fût présentée sous forme de volume regroupant pour le bénéfice de ceux intéressés en la matière les expressions les plus signifcatives de cette pensée.

Walter Reuther est avant tout un homme d'action. Leader incontesté d'un des principaux et les plus dynamiques syndicats nord-américains, il a constitué à lui seul depuis déjà une vingtaine d'années, l'avant-garde de la pensée syndicale dite «progressive à l'intérieur du mouvement du travail organisé en Amérique du Nord. Un des premiers organisateurs du C.I.O. à partir de 1937 dans l'industrie de l'automobile, Walter Reuther est vite devenu le prototype du chef syndical de la \& nouvelle vague $\gg$ du syndicalisme industriel qui prit son essort aux Etats-Unis avec l'avènement de Franklin D. Roosevelt à la Maison Blanche et de son New Deal des années 1933-35.
Mais à la différence de plusieurs autres pionniers du \& nouvel unionisme 》 américain de l'entre-deux-guerres, Reuther ne s'est pas contenté de mettre sur pied et de consolider un syndicalisme de masse puissant en effectifs et en moyens de revendication sur le plan d'un marché du travail élargi, à l'aide d'une convention collective aux dimensions neuves; il a aussi repensé par lui-même l'ensemble de la \&philosophie > du travail organisé dans une société d'entreprise privée à l'occasion des grands problèmes qui l'ont confronté au cours de sa carrière de chef syndical et de négociateur dans un des secteurs les plus représentatifs de l'économie américaine.

Ce sont les principaux thèmes de cette pensée qui nous sont aujourd'hui présentés sous forme d'anthologie. Débutant avec le rapport de 1940 sur l'utilisation de l'industrie de l'automobile dans le programme de production d'avions militaires, les documents présentés se ramènent à trois groupes. En premier lieu viennent ceux qui se rapportent à certains événements historiques de la vie syndicale américaine. Nous y trouvons le discours de Reuther à la dernière convention du Congrès des Organisations industrielles précédant la fusion avec la Fédération américaine du Travail en 1955, ainsi que son témoignage historique devant le Comité McClellan enquêtant sur les pratiques syndicales.

Puis vient le groupe des analyses pénétrantes que le président des Travailleurs-Unis de l'Automobile fit au cours des années, relativement aux problèmes impliquant directement le bien-être des travailleurs: l'automation et ses conséquences, la politique des prix administrés dans l'industrie de l'automobile, les problèmes de croissance économique, les coûts \&humains \ du chômage.

Enfin, nous sont offertes les vues de Reuther sur certains grands problemes d'ordre national et international: l'anticommunisme, l'énergie atomique, l'éducation, les droits civils, les relations internationales.

A travers ces témoignages perce la forte personnalité, la pénétration ainsi que la probité du caractère d'un homme qui incarne l'aile marchante du syndicalisme américaine.

Jean-Réal Carden 